\title{
Freak waves in 2005
}

\author{
I. I. Didenkulova ${ }^{1,2,3}$, A. V. Slunyaev ${ }^{1}$, E. N. Pelinovsky ${ }^{1,2}$, and C. Kharif ${ }^{4}$ \\ ${ }^{1}$ Institute of Applied Physics, Russian Academy of Sciences, Nizhny Novgorod, Russia \\ ${ }^{2}$ Nizhny Novgorod State Technical University, Nizhny Novgorod, Russia \\ ${ }^{3}$ Institute of Cybernetics, Tallinn University of Technology, Tallinn, Estonia \\ ${ }^{4}$ Institut de Recherche sur les Phénomènes Hors Equilibre, Marseille, France
}

Received: 29 August 2006 - Revised: 28 November 2006 - Accepted: 29 November 2006 - Published: 6 December 2006

\begin{abstract}
Information about freak wave events in the ocean reported by mass media and derived from personal observations in 2005 is collected and analysed. Nine cases are selected as true freak wave events from a total number of 27 mentioned. Besides rogue waves in the open sea, the problem of freak wave events on the shore is emphasized. These accidents are related to unexpected wave impact upon the coast and shore constructions or to sudden intensive flooding of the coast. Of the nine events considered reliable here, three events correspond to open-sea cases, while the six others occurred nearshore.
\end{abstract}

\section{Introduction}

Descriptions of unusually high waves appearing on the sea surface for a short time (freak, rogue or killer waves) have been considered as a part of marine folklore for a long time. A number of instrumental registrations have appeared recently making the community to pay more attention to this problem and to reconsider known observations of freak waves: some of them are collected in the paper by Mallory (1976), by Torum and Gudmestad (1990), by Olagnon and Athanassoulis (2001), by Kharif and Pelinovsky (2003) and by Rosenthal (2003). Nowadays the crucial role of these waves in many accidents, that led to ship damages and people losses, is certain.

Although the number of instrumental freak wave records is hundreds, it is still insufficient to build reliable statistics and to give a definite answer about their nature. Regions with strong currents were suspected dangerous first. Indeed, they possess inherent strongly inhomogeneous conditions for the surface wave propagation, which may result in energy concentration in some zones and thus abnormal wind wave

Correspondence to: I. I. Didenkulova

(dii@hydro.appl.sci-nnov.ru) amplification (Peregrine, 1976; Lavrenov, 1998). At the same time various observations carry reports about this phenomenon in different areas of the world ocean with no significant respect to the presence of strong currents. This was evidently confirmed by recent freak wave registrations from the space European satellite ERS-2 (Rosenthal et al., 2003).

Different theoretical effects have been suggested to explain freak wave events and corresponding models have been developed (Olagnon and Athanassoulis, 2001; Kharif and Pelinovsky, 2003; Rosenthal, 2003). Commonly freak waves in the open sea are the subject of investigation. They may grow due to wave focusing of different kinds: because of the action of external forces or due to the surface wave dynamics. Nonlinear self-modulation is one of the most probable ways of rogue wave generation. It acts in sufficiently deep water, although Chien et al. (2002) report about 140 freak wave events in the coastal zone of Taiwan in the past 50 years (1949-1999) and proceed with 175 instrumental records during 1996. This claims the existence of freak waves off the deepwater areas.

Rogue waves in the open sea may be measured by altimeters installed on offshore platforms or deployed buoys, or after SAR image processing. These registrations are trustworthy and may be used for accurate analysis. Similar events are also observed near-shore. In this case, these accidents are naturally seen by eyewitnesses. Their mentioning becomes more frequent, and they broaden the area of possible freak wave occurrence. Usually freak wave events onshore result in a short time sudden flooding of the coast, or in a strong impact upon steep banks or coastal structures. Some descriptions of these accidents are given in the abovementioned reviews and further in Rabinovich and Monserrat (1998) and in Dean and Dalrymple (2002). Some of them are explained as "meteorological tsunamis", but this class may be broader (see for instance the theoretical study of edge waves by Kurkin and Pelinovsky, 2002). 
Table 1. Freak waves in the open sea in 2005.

\begin{tabular}{|c|c|c|c|c|c|}
\hline Event & Location & $\begin{array}{l}\text { Freak wave } \\
\text { height esti- } \\
\text { mation }\end{array}$ & $\begin{array}{l}\text { Maximum } \\
\text { signifi- } \\
\text { cant wave } \\
\text { height } \\
\text { estimation*) }\end{array}$ & $\begin{array}{l}\text { Number of } \\
\text { waves }\end{array}$ & Damages \\
\hline 27 Jan, "Explorer" & $\begin{array}{l}\text { The Pacific Ocean ( } 650 \\
\text { miles south of Adak in } \\
\text { Alaska's Aleutian Islands) }\end{array}$ & $15 \mathrm{~m}$ & $7.2 \mathrm{~m}$ & 1 & $\begin{array}{l}\text { bridge window bro- } \\
\text { ken out, loss of } \\
\text { propulsion, injury of } \\
2 \text { people }\end{array}$ \\
\hline 14 Feb, "Grand Voyager" & $\begin{array}{l}\text { The Mediterranean Sea ( } 60 \\
\text { miles from Minorca) }\end{array}$ & $14 \mathrm{~m}$ & $2.4 \mathrm{~m}$ & 1 & $\begin{array}{l}\text { a broken bridge } \\
\text { window, damage } \\
\text { to electrical control } \\
\text { systems, a temporary } \\
\text { loss of propulsion, } \\
\text { and loss of all com- } \\
\text { munications; injury of } \\
20 \text { people }\end{array}$ \\
\hline 16 April, "Norwegian Dawn" & $\begin{array}{l}\text { The Atlantic Ocean (from } \\
\text { the Bahamas to New York) }\end{array}$ & over $21 \mathrm{~m}$ & $4 \mathrm{~m}$ & 1 & $\begin{array}{l}\text { Windows broken out, } \\
\text { diverted for repairs, } \\
\text { injury of } 4 \text { people }\end{array}$ \\
\hline
\end{tabular}

*) data of the Live Access Server

Although a number of possible physical explanations of freak wave generation have been suggested, the question about the real (or more probable) mechanism of freak waves formation in the real (typical) sea is not answered yet. This is an important problem that should be solved. An attempt to reveal the physical nature of freak waves on the basis of real observations has been undertaken in Slunyaev et al. (2005), but it needs more information to give the definite answer. Thus, collecting available freak wave registrations seems to be important and useful. We tried to gather and classify the observations of freak waves reported by the mass media and personally observed by the staff of the Institute of Applied Physics RAS during 2005. The collection was presented in the EGU Assembly in 2005 (Slunyaev et al., 2006). This work accompanies the serious studies of the ship accidents provided, for example, in Lavrenov (1998), Haver (2004), Toffoli et al. (2005) and Lechuga (2006). Files of ship insurance and classification companies as well as files of coastal rescue services may contain a much larger amount of similar events in the open sea.

Impressed eyewitnesses report on these accidents and thus, generally speaking, only hazardous huge waves are in the focus of this kind of study. It should be understood that only some part of observed freak events has appeared in the media. On the other hand, many of them may be just regular storm waves. In interactions of waves with a ship hull or with a seawall, or in cross-seas, just two slightly above average waves may form a very high hump, that generally is not understood as a freak wave. The shape of the hull or of the shore constructions may additionally enhance this effect. The transience of the observation and the lack of information prevent accurate interpretation of the observed waves. It may be considered as a kind of testimony for the abnormal character of the waves that the described accidents are quite rare. They could have been expected more regular if they had resulted from usual superposition and geometries of the ships and coasts.

We have selected nine cases among a total number of 27 reports as reliable and more or less satisfying the freak wave definition accidents. We split the registrations into two parts: freak waves in the open sea and freak waves on the shore. This division is caused by the significant difference in the ways of observation, available reliable information, and, probably, physical effects. Section 2 is devoted to how we determine and estimate the reliability of the freak wave event on the basis of available data. Section 3 describes trustworthy freak waves in the open sea registered during the year 2005; and Sect. 4 describes selected accidents near-shore. Discussion is given in Sect. 5 .

\section{Determining freak waves}

We have analyzed in total 27 "freak" events mentioned in 2005 and we have selected only nine of them as true freak waves (see map Fig. 1). Their descriptions are given in Sects. 3 and 4 and summarized in Tables 1 and 2.

The first problem that arises is selecting reliable freak events among the list of unusual registrations. In determining 
Table 2. Freak wave events on shore in 2005 .

\begin{tabular}{|c|c|c|c|c|c|c|c|}
\hline Event & Location & $\begin{array}{l}\text { Freak wave height } \\
\text { estimation }\end{array}$ & $\begin{array}{l}\text { Typical waves esti- } \\
\text { mation }\end{array}$ & $\begin{array}{l}\text { Offshore signifi- } \\
\text { cant wave height } \\
\text { estimation*) }\end{array}$ & $\begin{array}{l}\text { Number } \\
\text { of } \\
\text { waves }\end{array}$ & Estimatio & Consequences \\
\hline $\begin{array}{l}26 \text { Aug, Kalk } \\
\text { Bay }\end{array}$ & $\begin{array}{l}\text { The Atlantic Ocean } \\
\text { (South Africa) }\end{array}$ & over $9 \mathrm{~m}$ & & $4.5 \mathrm{~m}$ & 1 & reliable & $\begin{array}{l}\text { two people washed, } \\
\text { one seriously in- } \\
\text { juried }\end{array}$ \\
\hline $\begin{array}{l}14 \text { Sep, Blue } \\
\text { Bay }\end{array}$ & $\begin{array}{l}\text { The Black Sea } \\
\text { (near Gelendzhik, } \\
\text { Russia) }\end{array}$ & $1 \mathrm{~m}$ & $0.4-0.5 \mathrm{~m}$ & & 1 & reliable & \\
\hline $\begin{array}{l}16 \text { Oct, Mara- } \\
\text { cas Beach }\end{array}$ & $\begin{array}{l}\text { The Caribbean Sea } \\
\text { (Trinidad Island, } \\
\text { the Antilles) }\end{array}$ & over $7.6 \mathrm{~m}$ & $\begin{array}{l}\text { between the peak } \\
\text { waves there were } \\
\text { waves of } 3.6-5.5 \mathrm{~m} \\
\text { height }\end{array}$ & $1.5 \mathrm{~m}$ & 2 & definite & $\begin{array}{l}\text { damage on the } \\
\text { coast }\end{array}$ \\
\hline $\begin{array}{l}24 \text { Oct, Blake } \\
\text { de Pastino }\end{array}$ & $\begin{array}{l}\text { The Atlantic Ocean } \\
\text { (Grand Bahama, } \\
\text { the Bahamas) }\end{array}$ & $3.7 \mathrm{~m}$ & & $1.2 \mathrm{~m}$ & 1 & reliable & $\begin{array}{l}\text { one victim, about } \\
\text { hundred homes } \\
\text { damaged }\end{array}$ \\
\hline $\begin{array}{l}11 \text { Nov, Port } \\
\text { Orford }\end{array}$ & $\begin{array}{l}\text { The Pacific Ocean } \\
\text { (Southern Oregon, } \\
\text { USA) }\end{array}$ & & & up to $3.8 \mathrm{~m}$ & 1 & $\begin{array}{l}\text { reliable, } \\
\text { indirect } \\
\text { testi- } \\
\text { monies }\end{array}$ & $\begin{array}{l}\text { two victims, one } \\
\text { injured }\end{array}$ \\
\hline $\begin{array}{l}10 \text { Dec, Petit } \\
\text { Havre }\end{array}$ & $\begin{array}{l}\text { The Caribbean Sea } \\
\text { (Guadeloupe, the } \\
\text { Antilles) }\end{array}$ & $2 \mathrm{~m}$ of runup height & $\begin{array}{l}\text { up to } 1 \mathrm{~m} \text { of runup } \\
\text { height }\end{array}$ & & 1 & reliable & \\
\hline
\end{tabular}

*) data of the Live Access Server

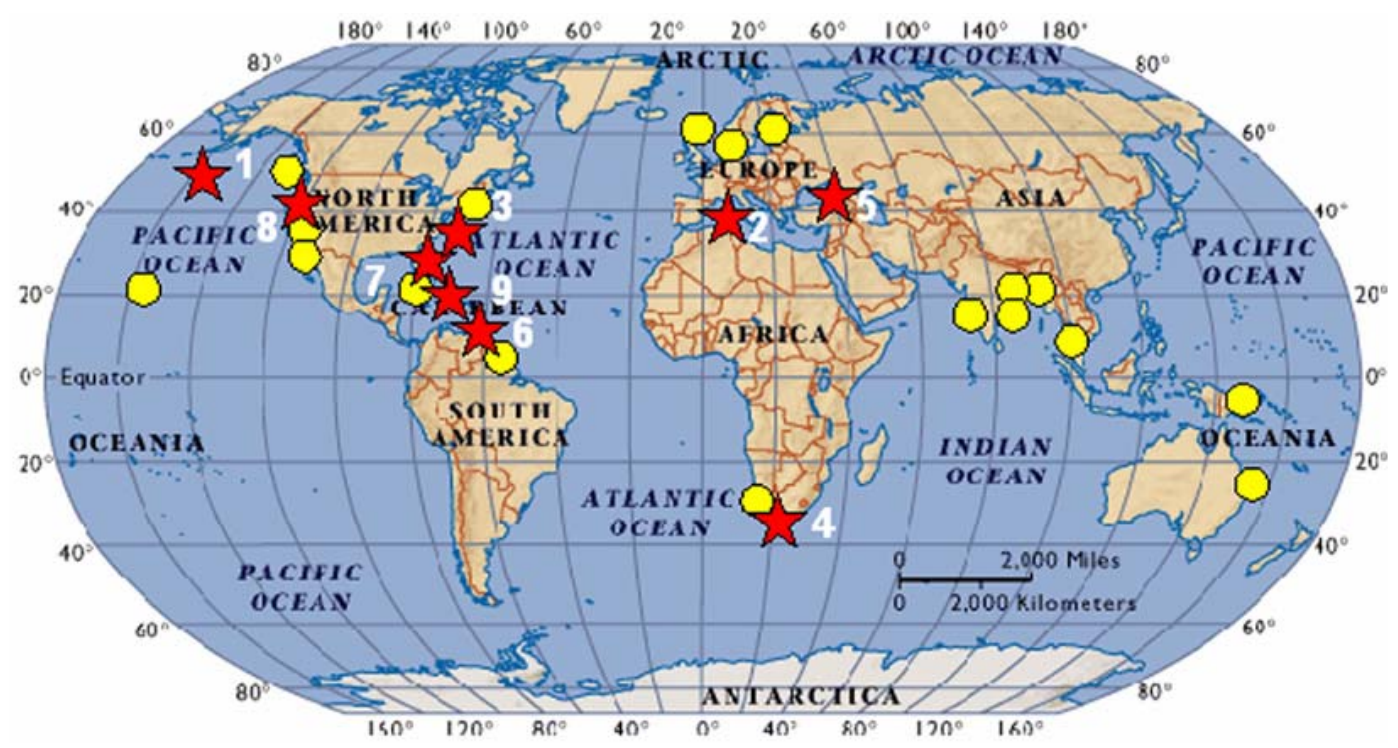

Fig. 1. Events selected as true freak waves are marked by red stars (1 - „Explorer”, 2 - "Grand Voyager“, 3 - "Norwegian Dawn”, 4 - Kalk Bay, 5 - Blue Bay, 6 - Maracas Beach, 7 - Blake de Pastino, 8 - Port Orford, 9 - Petit Havre); yellow circles mark all other reported cases when abnormally large waves were observed.

true freak waves we require first that this wave (or several waves) should appear suddenly. This is a subjective property usually related to the freak wave phenomenon; it seems to be always true for the observations since this is a feature that commonly impresses eye-witnesses. At the same time there should be no evident sources for abnormally high waves, such as earthquakes, landslides, etc.
Secondly, a freak wave is supposed to be much greater and more dangerous than its neighbors. The widely accepted definition of a freak wave is based on the amplitude criterion (the abnormality index): a freak wave is at least twice higher than the significant wave height. The threshold value of this ratio is sometimes supposed higher, and other extra conditions may be requested, but even this simplest definition may be difficult to be ascertained in our case. 
The freak waves measured by a device are considered reliable, although even this data may be doubtful (see Forristall, 2005). The way of defining the peak wave height in a time series is standard: it is the maximum vertical distance between the crest and neighboring troughs. The definition of the significant wave contains some averaging over ensemble of individual waves (the average height of $1 / 3$ of the highest waves in an ensemble) or is based on the processed spectrum of waves. All the accidents collected in this paper are not instrumentally measured. Thus, both the height of the observed freak waves and significant heights should be defined basing on some, generally speaking, indirect information with different levels of reliability.

The information about freak waves in the open sea seems to be rather reliable, since these observations are typically made by crews of large ships (and plenty of passengers). The waves in the open sea are less changeable if compared to coastal regions and onshore; forecasting and monitoring weather and wave conditions log-books are sometimes available and may be used in the study. The peak wave height may be estimated by the visual registration of the crew when the ship constructions are used as reference points. Significant wave height may be taken from the available data sources of wave monitoring for naval needs. Reports about freak waves made by crews of small ships (a private yacht, for example) might be considered less reliable since this staff may be worse organized, less experienced and disciplined; but they are not present in our list of freak waves observations.

The number of people in the coastal zone of the world ocean is, of course, much larger than in the open sea. Therefore, it is reasonable that the numbers of observed near-shore large waves and witnesses turn out to be greater. But it is much more difficult to estimate the trustworthiness of these accidents. We suggest the following criteria of reliability in this case:

i) instrumental registration (including photos of waves) is definite;

ii) reliable registration is proved by direct testimonies: presence of many witnesses, or visual definite registrations of high waves or runups that may be estimated referring to the shoreline relief or coastal constructions. Indirect arguments proving the reliability and abnormality of the wave may be also used (such as the case of 11 November in Port Orford (USA), described in Sect. 4, with an aged woman: an elderly lady is assumed to be smart and cautious enough to keep herself far from dangerous waves);

iii) all other reports are dubious.

It is necessary to remark that the manifestations of the coastal freak waves may be manifold, both due to the complexity of the problem configuration and to different active physical mechanisms supporting the phenomena. We cannot confidently classify the observed events, and therefore put them all together. The corresponding definition that marks out some events as freak waves cannot be always applied. Since waves are much more variable in the shore, the estimation of the significant wave height cannot be based on the sea waves monitoring aimed at naval purposes. The direct projection of the freak wave theory developed for the open sea in the case near-shore is also doubtful, because other physical mechanisms may enhance the waves. Typically, the freak wave event on the shore challenges the observers by an extraordinary wave splash or runup, but not by the individual wave height. Thus, the strict amplitude criterion is actually cancelled for the case of freak wave events on the shore in our present study.

Unfortunately, in many cases we have to rely on the publications of mass media, such as newspapers and news blocks in the Internet. This information is not always dependable. In many cases the multiple mentioning of an accident is based on one source of information that cannot be verified. Two freak wave events were observed by the staff of the Institute of Applied Physics (Blue Bay, Russia and Petit Havre, Guadeloupe, see Sect. 4) and may be considered as reliable, although the numbers of witnesses were small.

\section{Freak waves in the open sea}

There were only three reliable registered accidents eventually caused by freak waves in the open sea in 2005 . The data of these three events are presented in Table 1. The descriptions of these events are given below.

\subsection{January, cruiser "Explorer"}

The 591-ft cruise ship "Explorer" (former "Olympic Explorer") lost power in three of its four engines when a 50-foot $(15 \mathrm{~m})$ wave broke bridge windows, damaged controls and injured two crew members. The ship was 650 miles south of Adak in Alaska's Aleutian Islands about 1300 miles southwest of Anchorage. Crew members were able to start a second engine and the ship "limped" to Honolulu for needed repairs. This event is reported by Lemire (2005), in Schwabedissen (http://www.esys.org/news/sos_0501.html, 2005) and in the website "Events at sea" (http://www.cruisejunkie.com/ events2005.html). The way of estimating the freak wave height it is not certainly defined, but it seems typical to make these estimations basing on the levels of damages and watering with respect to the waterline. Following the significant wave information given in the website "Live Access Server" (http://ferret.pmel.noaa.gov/Ferret/LAS) a storm area moving not far from the Aleutian Islands may be marked out. Although there is no data for the day of the freak wave event registration, the maximum estimation of the significant waves during this storm in the neighboring days is $7.2 \mathrm{~m}$. The "Live Access Server" contains the data from several satellites: Jason-1 (CNES and NASA), TOPEX/Poseidon (NASA 


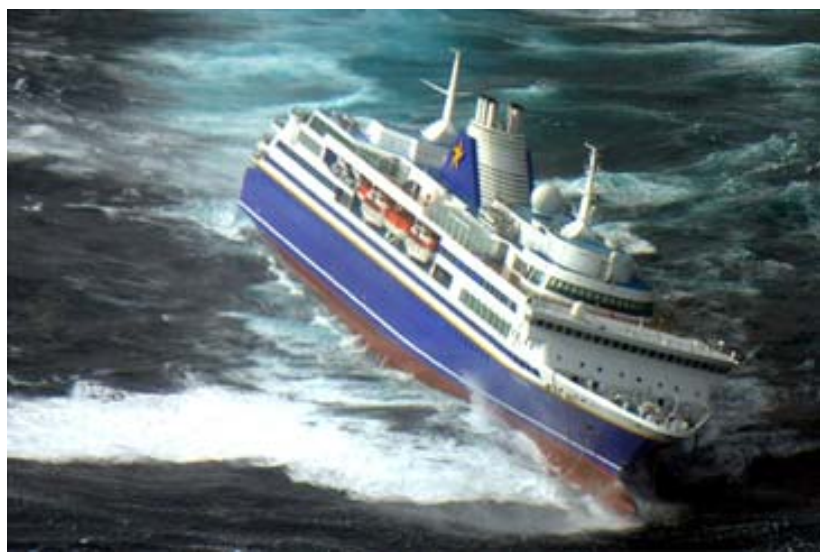

Fig. 2. The cruiser "Voyager" damaged by a 15-meter wave on 14 February (Schwabedissen and Walter: http://www.esys.org/news/ grand_voyager.html, 2005).

and CNES), Envisat (CNES and ESA), GFO (NOAA) with global geographic coverage. The lowest resolution is $1^{\circ}$ Mercator grid. Near-real time data are produced twice a week. The description of all the data, its processing, reliability and data sources are provided on the website. We analyze the data from each satellite and find the maximum wave from all satellites.

\subsection{February, cruiser "Grand Voyager"}

In a bizarre coincidence, just two weeks after the previous event, the ship sister of "Explorer" was damaged by a similar wave (46ft) in the Mediterranean. "Grand Voyager" (former "Voyager"), with more than 700 passengers on board, was on a voyage from Tunis to Barcelona when it was caught in a storm and hit by a huge wave while approximately 60 miles from Minorca. The wave reportedly struck the bridge area and damaged electronic equipment and caused engine failure for a period of time (Fig. 2). A nearby LPG tanker rushed to the scene and stood by while the crew attempted to restart the engines (Landry: http://cruise-chat.com/eve/forums/a/ tpc/f/533601132/m/339107609/inc/-1，2005; Schwabedissen and Walter: http://www.esys.org/news/grand_voyager. html, 2005; "Events at sea": http://www.cruisejunkie.com/ events2005.html, 2006). The maximum significant wave height for that part of the Mediterranean on 14 February is estimated as $2.4 \mathrm{~m}$ (Live Access Server).

\subsection{April, cruiser "Norwegian Dawn"}

Another 965-foot cruiser with more than 2000 passengers on the way from the Bahamas to New York was struck by a rogue wave at least $21 \mathrm{~m}$ height. The wave flooded cabins, injured passengers and forced the liner to stop for emergency repairs: "It was pure chaos! Our captain, who has 20 years on the job, said he never saw anything like it", as people

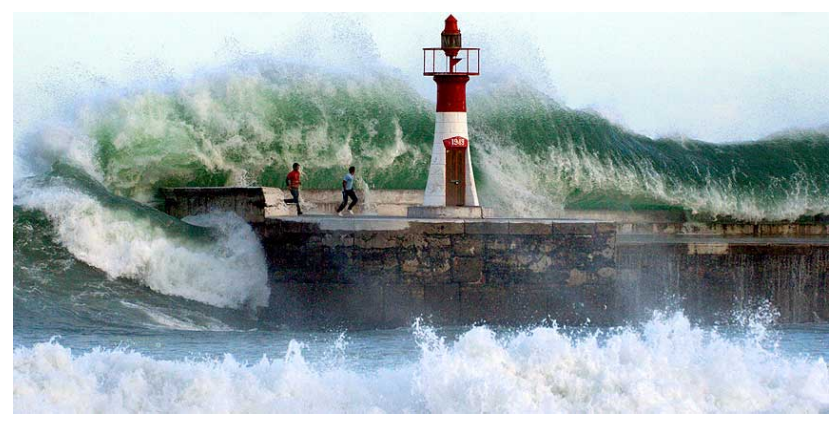

Fig. 3. A wave over $9 \mathrm{~m}$ washed two people off the breakwater in Kalk Bay on 26 August; photo by P. Massie (Hunter: http://www. weathersa.co.za/Pressroom/2005/2005Aug31ExtremeWaves.jsp, 2005).

claimed. This event is widely described in mass-media (see for instance Lemire, 2005; Broad, 2006). The maximum significant wave height in that area on that day was $4 \mathrm{~m}$ (Live Access Server).

\section{Freak wave events on shore}

We have selected only six accidents as true freak wave events near-shore. Their data are gathered in Table 2. To have a quantitative measure of waves in those regions we complete the information with significant wave height nearby offshore (data of satellite observations).

\subsection{August, Kalk Bay}

A wave washed two people off the breakwater in Kalk Bay (South Africa); both were rescued, although one received serious head injuries (Hunter: http://www.weathersa.co.za/ Pressroom/2005/2005Aug31ExtremeWaves.jsp, 2005). The wave height was over $9 \mathrm{~m}$ (Fig. 3). The offshore significant wave height near South Africa coast was up to $4.5 \mathrm{~m}$ (Live Access Server). It is remarked that a similar case was registered on 21 April 1996, at the same place, when three people were washed off; only one survived that time (Hunter: http://www.weathersa.co.za/Pressroom/2005/ 2005Aug31ExtremeWaves.jsp, 2005). And recently in 2006 on 22 July, a 60-year-old grandfather was swept off Kalk Bay harbour (Ndenze, 2006).

\subsection{September, Blue Bay}

An anomalously high surface wave was observed in Blue Bay in the Black Sea (near the town of Gelendzhik, Russia) during the measurements of film slicks conducted by the staff of the Institute of Applied Physics, Nizhny Novgorod, Russia. The boat was sailing at $40-50 \mathrm{~m}$ from the coast (the depth was about 2-3 m), when a single large breaking wave appeared at $15-20 \mathrm{~m}$ from the boat. It exceeded the typical 

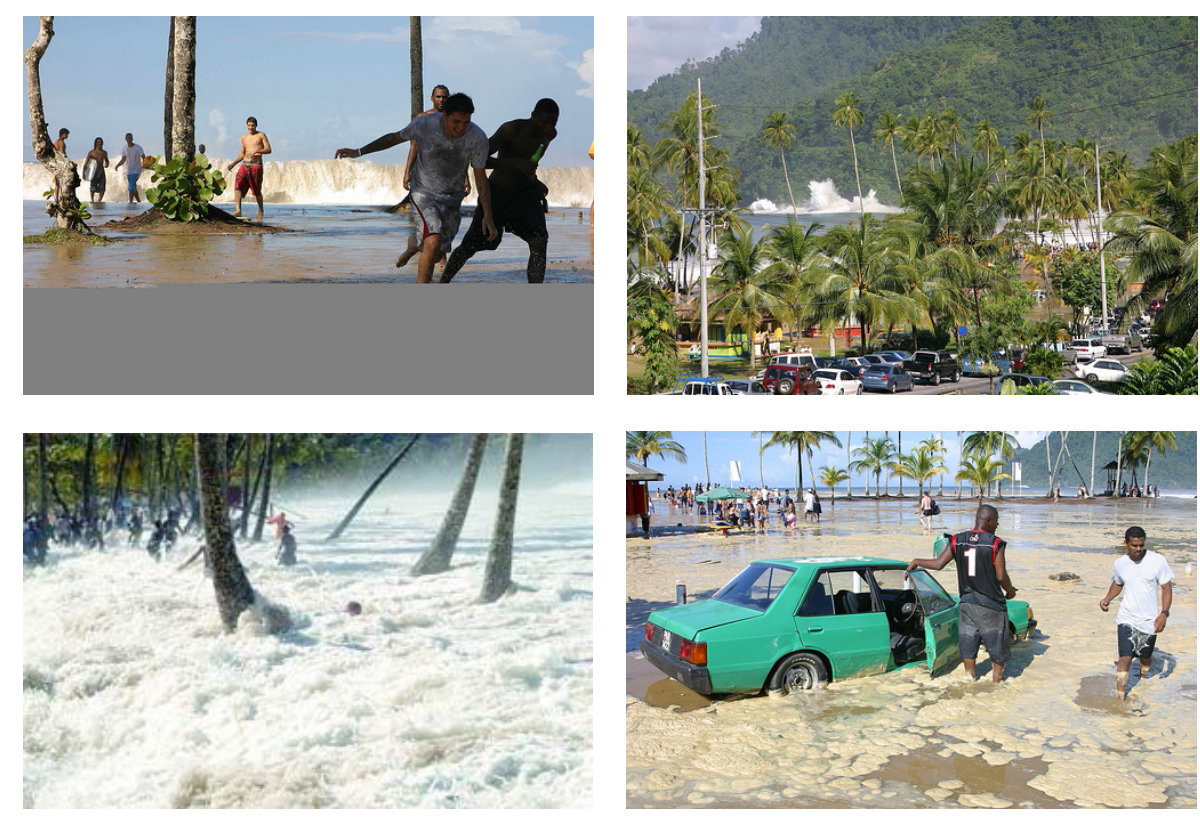

Fig. 4. The waves in Maracas Beach on 16 October (Stapleton, 2005).

waves about two times $(1 \mathrm{~m}$ against $40-50 \mathrm{~cm})$, passed the boat and broke at the coast (Ermakov and Vasilinenko, 2005).

\subsection{October, Maracas Beach}

There was panic at Maracas Beach (Trinidad Island, the Antilles), when a series of towering waves, many more than 25 feet high, sent seabathers, vendors and lifeguards running for their lives (Fig. 4). Around 02:15 p.m., two waves, described by lifeguards as more than 25 feet high, followed each other simultaneously, taking everyone by surprise. As an eyewitness said, "you have waves that are coming in at 20 to 25 feet and in between you have sets of 12 to 18 feet." The waves raced past the shoreline onto vending stalls, before crossing the roadway and flooding out the car park and bake and shark vendors' stalls on the northern side of the main thoroughfare. Refrigerators, stoves and gas tanks stood in knee-high water inside vendor stalls. The swells, which began pounding the North Coast shoreline at around 11:00 a.m., continued late into the evening. There were reports that pirogues at Las Cuevas, Blanchisseuse and La Fillette were destroyed by the swells (Stapleton, 2005). The offshore significant wave height for Maracas Bay was about $1.5 \mathrm{~m}$ (Live Access Server).

\subsection{October, Blake de Pastino}

Grand Bahama (the Bahamas) was rocked by a big wave on 24 October. Witnesses describe storm surges 12 feet (3.7 $\mathrm{m}$ ) high, which swept away more than a hundred homes and killed at least one villager, a 15-month-old child who drowned in the sea swells. "This was a massive wave that came in, one that was beyond any way to control it... You couldn't do anything with that one. I saw the wave came up about as high as the roof of this house and the roof is for sure 12 feet or more", people said (National Geographic News, 2005). The consequences of this event are shown in Fig. 5. Although it was a heavy storm caused by Hurricane Wilma, the offshore significant wave height for that day was not very large - about $1.2 \mathrm{~m}$ (Live Access Server).

\subsection{November, Port Orford}

One more case happened in Port Orford (Southern Oregon, USA). A wave swept three people into the Pacific Ocean, killing two and injuring one (The Seattle Times, 2005). We do not know anything about the wave that swept those people, but one of them is reported aged. Pamela Flynn was 72 years old. This should imply that the rogue wave was unexpectedly high. The offshore significant wave height on that day was up to $3.8 \mathrm{~m}$.

\subsection{December, Petit Havre}

An unexpected flooding of the Caribbean coast was observed in Guadeloupe (the Antilles) by one of the authors (I.D.). At the point called Petit Havre the coast $2 \mathrm{~m}$ off the shoreline was suddenly covered by water (usual runup is up to $1 \mathrm{~m}$ ); during other $4 \mathrm{~h}$ nothing similar happened.

\section{Discussion}

The major number of observed freak wave events is related to the near-shore zone. This is evidently explained by the 

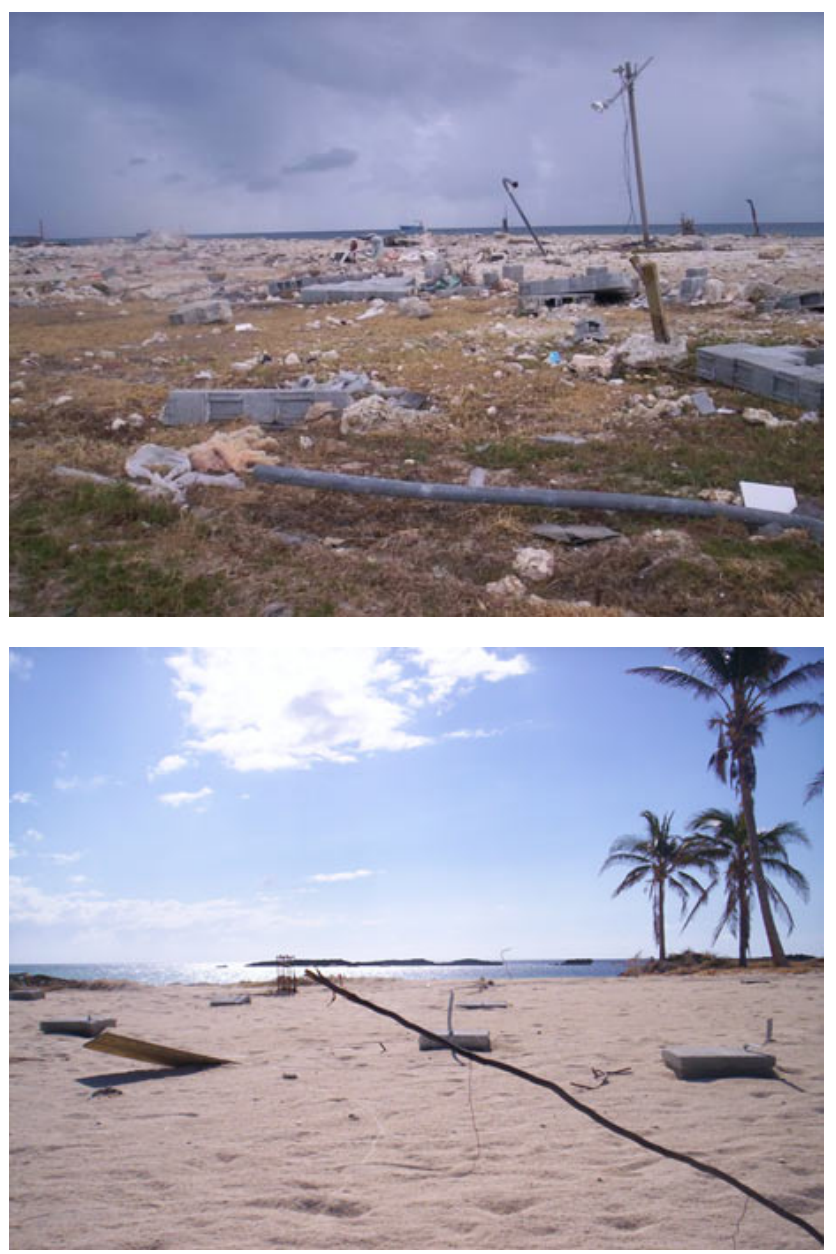

Fig. 5. The Bahamas, rocked by a big wave on 24 October (National Geographic News, 2005).

greater number of potential witnesses, and a higher rate of dubious accidents. Figure 1 shows the locations of the events in 2005 suggested (dots) and selected (stars) as true freak wave events. The number of accidents near the shore remains greater (six events against threein the open sea).

All available observations of freak waves in the open sea are made by crews and passengers of large cruiser ships what makes them reliable. We suppose the freak wave on Maracas Beach to be definite, since many photos and evidences are available. The case at the Bahamas is reliable, but not definite because it happened during Hurricane Wilma and could be caused by regular storm waves. The reliability of the accident in Port Orford has been already discussed: it is supposed reliable, although it is based on indirect arguments. Two cases were observed by the staff of the Institute of Applied Physics (Blue Bay and Petit Havre) and are considered reliable. The case in Kalk Bay seems to be reliable, especially if we bear in mind two other similar cases reported in this bay.

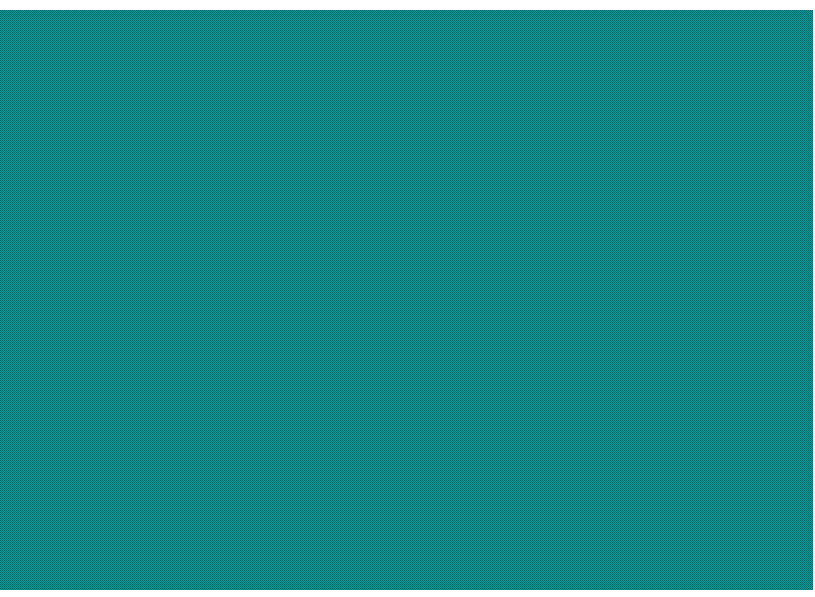

(a)

(b)

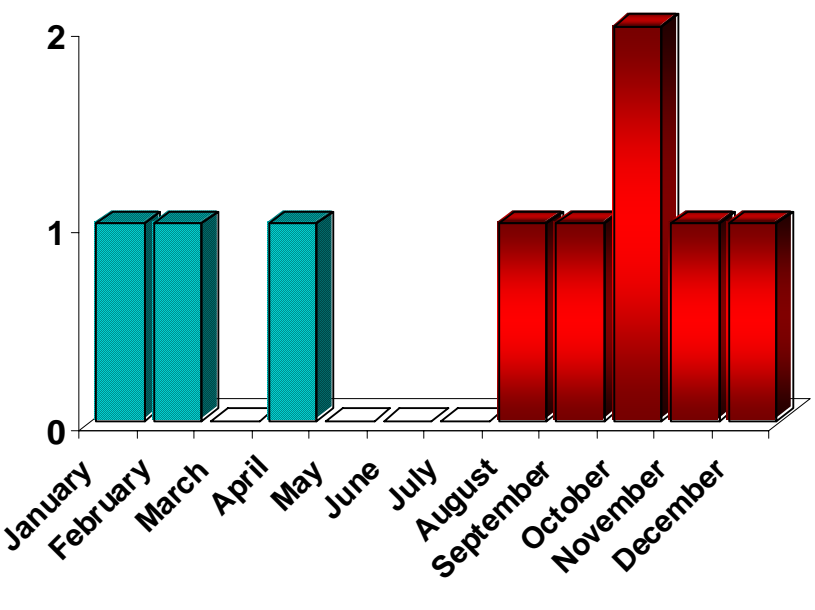

Fig. 6. Month distribution of all collected observations about abnormally high waves (a) and selected ones as true freak wave events (b). Accidents that occurred in the open sea are coloured by blue with shading; those at a coastal zone are marked by red.

The distribution of reported freak wave events (suggested and reliable) during the year is presented in Fig. 6. It is difficult to build statistics on the basis of such a small number of cases, although some regularity may be easily caught from these plots: the accidents in the open sea prevail in winter time, although the near-shore accidents happen during the second half of the year. This should be certainly related to the swimming and tourist seasons, but may have other reasons.

The absolute heights of the reported waves in the open sea are not outstanding, a little higher than $20 \mathrm{~m}$, but they appear suddenly and significantly exceed surrounding waves. The estimations of freak wave excess over significant waves made with the help of available data show sometimes unbelievable results (see the accident with Norwegian Dawn in Table 1). The abnormality index $H_{\max } / H_{\text {significant }}$ approaches five, although the maximum instrumentally registered value to our knowledge does not exceed four (Divinsky et al., 2004; Stansell, 2004). This makes the available data doubtful. In all 
cases considered here there was a single wave without precursor and after-waves, except the event on Maracas Beach, where a series of "towering waves" were observed.

About ten years ago it was supposed that freak waves occur much rarer than they are observed: these reports were questioned. Now the turning point is passed, and it is understood that freak waves happen much more frequent than they are observed. Reported cases of observations and measurements for the Taiwan coast (Chien et al., 2002) confirm this conclusion. We tried to collect and classify the freak waves observed by eyewitnesses during the year of 2005 . The main goal of this research is to take into consideration different possible manifestations of this phenomenon to be able to comprehend adequately the physics, role and potential possibilities of these waves. The problem of near-shore freak wave events should be studied further, since registrations of these events become absolutely reliable (see photos in Figs. 4, 5), and they cause real destruction and people losses. This collection is certainly incomplete and we would like to stimulate collecting similar reliable cases to be able to understand the physics of freak wave events.

Acknowledgements. This research is supported for Russian coauthors by grants from INTAS (03-51-4286, 04-83-3032) and RFBR (05-05-64265); Marie Curie network SEAMOCS (MRTN-CT-2005-019374) and Scientific Schools of B. V. Levin (8043.2006.5) and V. I. Talanov (6043.2006.2). Particularly, this study is supported for C. Kharif by grant ARCUS. I. I. Didenkulova thanks T. Soomere for the provided data of the accident on14 February. E. N. Pelinovsky thanks the Centre National de la Recherche Scientifique for the invitation as Director of Research in the Institut de Recherche sur les Phénomènes Hors Equilibre (IRPHE, Marseille, France) to study freak waves.

We are grateful to T. Soomere whose remarks enabled to improve this paper.

Edited by: S. Tinti

Reviewed by: T. Soomere

\section{References}

Broad, W. J.: Rogue Giants at Sea. New York Times, 11 July 2006. Chien, H., Kao, C.-C., and Chuang, L. Z. H.: On the characteristics of observed coastal freak waves, Coastal Eng. J., 44(4), 301-319, 2002.

Dean, R. G. and Dalrymple, R. A.: Coastal Processes with Engineering Applications, Cambridge University Press, 2002.

Divinsky, B. V., Levin, B. V., Lopatukhin, L. I., Pelinovsky, E. N., and Slyunyaev, A. V.: A freak wave in the Black Sea: observations and simulation, Doklady Earth Sciences, 395A, 438-443, 2004.

Ermakov, S. A. and Vasilinenko, N. I.: About one observation of an abnormal wave in the coastal zone of the Black Sea, Izvestiya, Russian Academy of Engineering Science (in Russian), 14, 8081, 2005.

Events at sea: http://www.cruisejunkie.com/events2005.html, 20 August 2006.
Forristall, G. Z.: Understanding rogue waves: Are new physics really necessary?, Rogue Waves 2005, edited by: Olagnon, M. and Provosto, M., Brest, Ifremer, 2005.

Haver, S. A.: Possible freak wave event measured at the Draupner jacket January 1 1995, Proc. of Int. Conf. "Rogue Waves 2004”, edited by: Olagnon, M. and Prevosto, M. (France, Brest, 2004), IFREMER, 2005, http://www.ifremer.fr/web-com/stw2004/rw/ fullpapers/walk_on_haver.pdf

Hunter, I.: Extreme Wave Conditions spread along the South African coast, http://www.weathersa.co.za/Pressroom/ 2005/2005Aug31ExtremeWaves.jsp, 31 August 2005.

Kharif, C. and Pelinovsky, E.: Physical mechanisms of the rogue wave phenomenon, Europ. J. Mech. B/Fluids, 22, 603-634, 2003.

Kurkin, A. and Pelinovsky, E.: Focusing of edge waves above sloping beach, Europ. J. Mech. B / Fluids, 21, 561-577, 2002.

Landry, D.: Voyager Damaged by Heavy Seas, http://cruise-chat. com/eve/forums/a/tpc/f/533601132/m/339107609/inc/-1, 14 February 2005.

Lavrenov, I.: The wave energy concentration at the Agulhas current of South Africa, Nat. Hazards, 17, 117-127, 1998.

Lechuga, A.: Were freak waves involved in the sinking of the Tanker "Prestige"?, Nat. Hazards Earth Syst. Sci., 6, 973-978, 2006 , http://www.nat-hazards-earth-syst-sci.net/6/973/2006/.

Lemire, J.: A long history of killer crests, New York Daily News, New York, N.Y., April 17, p. 2, 2005.

Live Access Server: http://ferret.pmel.noaa.gov/Ferret/LAS/, 2006.

Mallory, J. K.: Abnormal waves on the south-east of South Africa. Inst. Hydrog. Rev., 51, 89-129, 1974.

National Geographic News: Bahamas Rocked by “Tsunami” From Hurricane Wilma, 8 November 2005.

Ndenze, B.: Grandfather tells of freak wave ordeal, The Cape Times, 25 July 2006.

Olagnon, M. and Athanassoulis, G. A. (Eds.): Rogue Waves 2000, Ifremer, France, 2001.

Peregrine, D. H.: Interaction of water waves and currents, Adv. Appl. Mech., 16, 9-117, 1976.

Rabinovich, A. B. and Monserrat, S.: Generation of meteorological tsunamis (large amplitude seiches) near the Balearic and Kuril Islands, Nat. Hazards, 18, 27-55, 1998.

Rosenthal, W.: MaxWave. Rogue Waves: Forecast and Impact on Marine Structures, GKSS Research Center, Geesthacht, Germany, 2003.

Rosenthal, W., Lehner, S., Dankert, H., Guenther, H., Hessner, K., Horstmann, J., Niedermeier, A., Nieto-Borger, J. C., SchulzStellenfleth, J., and Reichert, K.: Detection of extreme single waves and wave statistics. Rogue Waves: Forecast and Impact on Marine Structures, GKSS Research Center, Geesthacht, Germany, 2003, Papers WP 1, 3, 2003.

Schwabedissen, V. T. and Walter, P. O.: Was passierte auf der "Grand Voyager"?, http://www.esys.org/news/grand_voyager. html (in German), 16 February 2005.

Schwabedissen, V. T.: "Explorer" auf dem Weg nach Honululu (in German), http://www.esys.org/news/sos_0501.html, 1 February 2005.

Slunyaev, A., Didenkulova, I., and Pelinovsky, E.: Freak waves in 2005, Geophys. Res. Abstr., ID-NR: EGU06-A-01666, 2006.

Slunyaev, A., Pelinovsky, E., and Guedes Soares, C.: Modeling 
freak waves from the North Sea, Appl. Ocean Res., 27, 12-22, 2005.

Stansell, P.: Distributions of freak wave heights measured in the North Sea, Appl. Ocean Res., 26, 35-48, 2004.

Stapleton, R.: Shock Wave. Vendors' stalls, car park over-run by 25 foot-high swirls, Trinidad \& Tobago Express, 17 October 2005.
The Seattle Times: Wave kills two in Southern Oregon, 11 November 2005 .

Toffoli, A., Lefevre, J. M., Bitner-Gregersen, E., and Monbaliu, J.: Towards the identification of warning criteria: analysis of a ship accident database, Appl. Ocean Res., 27, 281-291, 2005.

Torum, A. and Gudmestad, O. T. (Eds.): Water Wave Kinematics, Kluwer, Dordrecht, 1990. 